\title{
RESEARCH
}

\section{Association of low intake of milk and vitamin D during pregnancy with decreased birth weight}

\author{
Cynthia A. Mannion, Katherine Gray-Donald, Kristine G. Koski
}

An abridged version of this article appeared in the Apr. 25, 2006, issue of CMAJ.

\section{ABSTRACT}

Background: Some pregnant women may be advised or choose to restrict milk consumption and may not take appropriate supplements. We hypothesized that maternal milk restriction during pregnancy, which can reduce intakes of protein, calcium, riboflavin and vitamin $\mathrm{D}$, might represent a health risk by lowering infant birth weight.

Methods: We screened women between the ages of 19 and 45 years who were attending prenatal programs in Calgary, Alberta $\left(51^{\circ} \mathrm{N}\right)$ for low milk consumption $(\leq 250 \mathrm{~mL} / \mathrm{d})$. Using repeat dietary recalls, we compared these women and their offspring with women whose daily milk consumption exceeded $250 \mathrm{~mL}$ (1 cup). Birth weight, length and head circumference were obtained from birth records.

Results: Women who consumed $\leq 250 \mathrm{~mL} / \mathrm{d}$ of milk $(n=72)$ gave birth to infants who weighed less than those born to women who consumed more $(n=207 ; 3410 \mathrm{~g} \mathrm{v}$. $3530 \mathrm{~g}$, respectively; $p=0.07)$. Infant lengths and head circumferences were similar. Women who restricted milk intake had statistically significantly lower intakes of protein and vitamin D as well. In multivariate analyses controlled for previously established predictors of infant birth weight, milk consumption and vitamin $D$ intake were both significant predictors of birth weight. Each additional cup of milk daily was associated with a $41 \mathrm{~g}$ increase in birth weight ( $95 \%$ confidence interval $[\mathrm{Cl}]$ 14.0-75.1 g); each additional microgram of vitamin D, with an $11 \mathrm{~g}$ increase ( $95 \% \mathrm{Cl} \mathbf{1 . 2 - 2 0 . 7} \mathrm{g}$ ). Neither protein, riboflavin nor calcium intake was found to predict birth weight.

Interpretation: Milk and vitamin D intakes during pregnancy are each associated with infant birth weight, independently of other risk factors.

Cite this article as $C M A J$ 2006;174(9). DOI:I0.1503/cmaj.I04I388

$M$ ilk is an important source of vitamin D, calcium, riboflavin, protein and energy during pregnancy, yet many women choose or are advised to avoid drinking milk for a variety of reasons, including the prevention of allergies in their children. ${ }^{1}$ Limiting milk intake com- promises the quality of the maternal diet; ${ }^{2-5}$ women who avoid milk may not obtain adequate levels of vitamin $\mathrm{D}$, calcium, protein or riboflavin. Milk restriction is a risk factor for pregnancy-associated hypertension. ${ }^{6}$ Low vitamin D intake is associated with neonatal rickets ${ }^{7}$ and decreased birth weight. ${ }^{8}$ Inadequate consumption of riboflavin is associated with decreases in weight, ${ }^{9}$ length and head circumference of babies at birth. ${ }^{10}$

Although most nutrients in milk may be replaced from other foods or with supplements, vitamin D is found in few commonly consumed foods except for milk fortified with the vitamin. ${ }^{11}$ Dermal conversion of the precursor cholecalciferol to activated vitamin $\mathrm{D}$ is a seasonally unreliable source, particularly when the exposure of skin to sunlight is limited, ${ }^{12}$ and may not compensate for low nutritional intake. Under optimal conditions, 15 minutes of daily exposure of the hands and face to sun is required to produce adequate vitamin $\mathrm{D},{ }^{13}$ but this conversion is reduced by the prolonged winter season at more polar latitudes, ${ }^{14,15}$ by use of sunscreens with a sun protection factor (SPF) above $8,{ }^{16}$ and by ozone air pollution. ${ }^{13}$ People whose skin pigmentation is dark are more vulnerable than others to insufficient vitamin D conversion. ${ }^{16}$

In this study we compared the birth weight, crown-heel length and head circumference of newborns whose mothers restricted their intake of milk during pregnancy with the babies of those who did not.

\section{Methods}

Between May I997 and June 1999 we screened 209I women who attended prenatal classes at 3 hospitals in Calgary, Alberta. The study was approved by the Institutional Review Board of McGill University as well as by the Calgary Health Region Ethics Board.

Women were given an anonymous questionnaire that asked whether they would be willing to participate in an indepth study on dietary intake and pregnancy outcomes, and if they restricted dairy products for any reason. For consenting participants, a second questionnaire asked for demographic data, lifestyle characteristics (e.g., smoking habits, highest level of education achieved) and if they had certain metabolic conditions (e.g., diabetes, hypertension) or a multiple pregnancy. Only healthy mothers with singleton pregnancies were 
included; subjects with metabolic, cardiovascular or renal disorders (identified from self-reports or later medical-chart review) were excluded.

Of the 307 women initially screened who indicated that they restricted milk, 72 (24\%) agreed to participate. Since we did not wish to study a large sample of women who did not restrict their milk intake, we accepted available subjects only until we had about 3 times as many nonrestrictors as restrictors.

For purposes of analysis we defined restriction as the daily consumption of I cup ( $250 \mathrm{~mL}$ ) of milk or less. This amount was chosen because the Canada Food Guide for Healthy Eating recommends servings in cup measures; cup portions are easily recognizable; and it is known that I cup of milk supplies approximately $300 \mathrm{mg}$ of calcium, $90 \mathrm{IU}$ of vitamin D, $5 \mathrm{~g}$ of fat (in $2 \%$ milk), $8.6 \mathrm{~g}$ protein, $0.43 \mathrm{~g}$ riboflavin and $536 \mathrm{~mJ}$ (I28 kcal) energy. ${ }^{17}$ We anticipated that women who consumed less than a cup of milk per day would be unlikely to achieve the recommended adequate intakes of vitamin D $(200 \mathrm{IU}=5 \mu \mathrm{g})$ and calcium (I0oo $\mathrm{mg} / \mathrm{d})$ from other food sources without vitamin and mineral supplementation. In a well-nourished population such as our own, concerns about meeting the estimated average requirement (EAR) for protein and riboflavin are fewer, since these nutrients are more easily replaced by other commonly consumed foods such as meat, grains and cereals.

Trained nutritional interviewers telephoned the study subjects on random days of the week, including Saturday and Sunday. Each participant was interviewed 3 or 4 times $(86 \%$, 4 times). We supplied interviewers and participants with a styrofoam cup (I95 mL), a plate ( $25 \mathrm{~cm}$ diameter), a bowl $(340 \mathrm{~mL})$ and a flexible $30-\mathrm{cm}$ ruler to assist with estimating quantities. Dietary data were collected by repeat 24 -hour diet- ary telephone recalls, an approach that has been has previously been validated. ${ }^{18,19}$

Food data were coded and entered into a software program for nutrient analysis. Food data were verified against original records by the data coder and reverified by a registered dietitian. Food and nutrient data were analyzed with the I997 CANDAT Nutrient Calculation System (Godin London Inc., London, Ont.) with use of the Canadian Nutrient File, ${ }^{20}$ plus information for 267 food items that was obtained from either food manufacturers' available data or the USDA Nutrient Database. ${ }^{21}$ Daily intake of vitamin and mineral supplements was recorded and added to each mother's dietary record. Interviewers also recorded if mothers currently smoked cigarettes and their highest level of education. We calculated maternal weight gain by subtracting pregravid weight from the last recorded maternal weight before delivery. Infant birth weight, crown-heel length and head circumference were taken from medical records.

Data for milk and nutrient intake (diet plus vitamin and mineral supplements) were first transformed to approximate normal distributions; the total variation was then adjusted with the I986 National Research Council method. ${ }^{22}$ We removed day-to-day variability so we could estimate prevalence of nutritional inadequacies compared with dietary reference intakes. ${ }^{23,24}$ The prevalence of inadequacy for a given nutrient was estimated by the percentage of mothers with intakes below the EAR, defined as the median of the requirement distribution for a population. ${ }^{23}$ Differences in numbers of restrictors ( $\leq$ I cup milk) and nonrestrictors ( $>$ I cup) who consumed less than the EARs for protein $(0.88 \mathrm{~g} / \mathrm{kg} / \mathrm{d})$ and riboflavin $(\mathrm{I} .2 \mathrm{mg} / \mathrm{d})$ were calculated and tested $\left(\chi^{2}\right)$. Dietary adequacy was estimated as the percentage of the group with

Table 1: Characteristics of women who did and did not restrict their milk consumption during pregnancy and measurements of their newborns

\begin{tabular}{|c|c|c|c|}
\hline \multirow[b]{2}{*}{ Characteristic } & \multicolumn{2}{|c|}{ Mean (standard deviation)* } & \multirow[b]{2}{*}{$\begin{array}{c}p \\
\text { value }\end{array}$} \\
\hline & $\begin{array}{c}\text { No restriction } \\
n=207^{*}\end{array}$ & $\begin{array}{c}\text { Restriction } \\
n=72^{*}\end{array}$ & \\
\hline \multicolumn{4}{|l|}{ Maternal } \\
\hline Age at delivery, yr & $31.2 \quad(4.3)$ & $30.0 \quad(4.54)$ & 0.11 \\
\hline Height, m† & $1.66(0.62)$ & $1.65 \quad(0.52)$ & 0.053 \\
\hline Weight before pregnancy, kg $\dagger$ & $63.9 \quad(10.0)$ & $62.0 \quad(13.36)$ & 0.25 \\
\hline Body mass index, $\mathrm{kg} / \mathrm{m}^{2}$ & $23.2 \quad(3.8)$ & $22.9 \quad(4.61)$ & 0.61 \\
\hline Gestational weight gain, kg & $16.8 \quad(5.4)$ & $15.9 \quad(6.65)$ & 0.32 \\
\hline Smoking, no. (\%)† & $(5.8)$ & $(5.56)$ & 0.97 \\
\hline University education, no. (\%)† & $94 \quad(46.5) \ddagger$ & $37 \quad(53.62) \ddagger$ & 0.33 \\
\hline Vitamin or mineral supplement use, no. (\%)† & $201 \quad(97.1)$ & $38 \quad(54.28) \ddagger$ & 0.050 \\
\hline \multicolumn{4}{|l|}{ Infant } \\
\hline Birth weight, g & $3530 \quad(466)$ & $3410 \quad(475) \ddagger$ & 0.07 \\
\hline Length, $\mathrm{cm}$ & 51.4 (3.6)‡ & (3.5)† & 0.46 \\
\hline Head circumference, $\mathrm{cm}$ & $34.6 \quad(1.5) \ddagger$ & $34.3 \quad(1.5) \ddagger$ & 0.19 \\
\hline
\end{tabular}


adjusted nutrient intakes below the EAR. We reported mean daily adequate intakes for calcium and vitamin $\mathrm{D}$ only because the scientific evidence to date for these nutrients is insufficient to derive EARs. ${ }^{23}$

We conducted a multivariable analysis to control for baseline indicators and nutrient intake. To determine the impact of milk restriction on birth parameters and to control for confounding variables, we developed a baseline regression model that included maternal education, height, gestational weight gain, body mass index and gestational age at delivery as independent variables. Smoking was not included because very few of the women smoked, and in our sample this variable was not related to birth weight. With these established predictors controlled for in our regression models, we then entered 5 foods or nutrients (cups of milk, vitamin D, calcium, riboflavin and protein) one at a time, since they were not independent, into I of 2 separate regression models: a milk intake model and a nutrient model. We chose birth weight, head circumference and crown-heel length as the dependent variables for either regression model. A $p$ value of 0.05 or less was considered statistically significant.

\section{Results}

During the 2 years of data collection spanning all 4 seasons, 307 of 2091 women attending prenatal classes (I4.7\%) indicated that they restricted their milk intake throughout pregnancy. The reasons cited for milk restriction were mainly lactose intolerance (usually self-diagnosed) and gastrointestinal discomfort.

Our study groups were similar for maternal age, weight before pregnancy, body mass index, gestational weight gain, smoking habits and education (Table I). Our sample population was healthy and well-educated; the majority cited Canada as their country of origin, smoked little and fell $(75 \%)$ within the recommended pregravid weight range.

Our pregnant women reported use of prenatal vitamins or mineral supplements, with lower use among milk restrictors (Table I). Energy and fat intakes were similar between the 2 groups, but significantly more milk restrictors had protein intakes below the calculated EAR for pregnant women than nonrestrictors. Riboflavin was unaffected by milk restriction - it is found in many other foods, and all women had adequate intakes (Table 2). ${ }^{23,24}$

When milk or vitamin D intakes were added into our multiple regression models, each emerged as a significant independent predictor of birth weight (Table 3), although neither predicted infant length or head circumference. When we controlled for previously established predictors of infant birth weight $t^{25}$ and used the $\beta$ coefficient to measure the magnitude of the effect of milk intake on birth weight, we found that for each cup of milk consumed per day, birth weight increased $4 \mathrm{I} \mathrm{g} \mathrm{(95 \%} \mathrm{confidence} \mathrm{interval} \mathrm{[CI]} \mathrm{I3-75} \mathrm{g)} \mathrm{on} \mathrm{average} \mathrm{(Table}$ 3). Thus, mothers who consume the 3 cups of milk per day that is recommended in Canada's Food Guide for Healthy Eating throughout pregnancy, at birth their infants would weigh I23 $\mathrm{g}$ more, on average. We also observed a positive relation between vitamin $D$ intake and birth weight: for each 1- $\mu \mathrm{g}$ in-
Table 2: Nutrient intakes of women who did and did not restrict their milk consumption during pregnancy

\begin{tabular}{|c|c|c|c|}
\hline \multirow[b]{2}{*}{ Nutrients } & \multicolumn{2}{|c|}{ Mean (standard deviation) } & \multirow[b]{2}{*}{$\begin{array}{c}p \\
\text { value }\end{array}$} \\
\hline & $\begin{array}{c}\text { No restriction } \\
n=207\end{array}$ & $\begin{array}{c}\text { Restriction } \\
n=72\end{array}$ & \\
\hline Energy, kcal & $2465 \quad(501)$ & 2424 (664) & 0.06 \\
\hline Fat, g/d & $83 \quad(25)$ & $87 \quad(33)$ & 0.33 \\
\hline Protein, g/d & $106 \quad(27)$ & $95 \quad(35)$ & 0.014 \\
\hline Protein, $\%<$ EAR $^{*}$ & $9.2 \dagger$ & $20.8 \dagger$ & 0.009 \\
\hline Riboflavin, mg/d & $6.5 \quad(4.8)$ & $6.6 \quad(6.1)$ & 0.80 \\
\hline Riboflavin, $\%<$ EAR $^{*}$ & 0 & 0 & \\
\hline Calcium, mg/d & $1864 \ddagger(497)$ & $1726 \neq(765)$ & 0.16 \\
\hline Vitamin $D, \mu g / d \neq$ & $13.1 \neq(4.5)$ & $7.9 \neq \quad(4.7)$ & $<0.001$ \\
\hline
\end{tabular}

crease of dietary vitamin D (food plus supplements), birth weight was increased by $11 \mathrm{~g}$ ( $95 \%$ CI 1.2-20.7 g; Table 3).

Similar regression models with protein entered as the sole nutrient indicated no independent contribution of protein to birth weight, infant length or head circumference in our otherwise healthy mothers. Neither did calcium or riboflavin predict birth weight (Table 3), infant length or head circumference (data not shown).

\section{Interpretation}

Our study showed that restricting fortified milk or vitamin D intake during pregnancy lowered infant birth weight in otherwise healthy, nonsmoking, well-educated mothers. This is an important finding because increasing numbers of women are restricting milk consumption during pregnancy, believing that it will lower fat intake, ${ }^{26-28}$ minimize weight gain, ${ }^{29}$ treat self-diagnosed lactose intolerance ${ }^{27}$ or prevent their children from developing allergies. ${ }^{1}$ Mothers and health professionals need to understand that this dietary practice may restrict essential nutrients and may negatively affect fetal development.

Our study is limited because only $24 \%$ of women who reported restricting milk consumption agreed to participate. We were not able to obtain maternal or infant blood samples for measurements of vitamin D; however, deficiency of this vitamin is well documented among Canadian women, ${ }^{30,31}$ including a recent study that found Canadian mothers and their infants to have high rates of vitamin D deficiency. ${ }^{32}$ Our vitamin D results are restricted to women living at latitudes associated with low sunlight exposure; milk-restricting pregnant women living in other areas may have better vitamin D status.

Vitamin D may be an important regulator of fetal growth. The vitamin reportedly increases fetal weight in women with hypocalcemia ${ }^{33}$ and improves maternal and fetal plasma concentrations of 25 -hydroxycholecalciferol. ${ }^{34}$ Low concentrations of vitamin $\mathrm{D}(<40 \mathrm{nmol} / \mathrm{L})$ have been associated with 
Table 3: Two regression models for predicting infant birth weight $(n=269)$

\begin{tabular}{|c|c|c|c|c|c|c|}
\hline \multirow[b]{2}{*}{ Characteristic } & \multicolumn{3}{|c|}{ Milk intake model ${ }^{*}$} & \multicolumn{3}{|c|}{ Nutrient model $†$} \\
\hline & \multicolumn{2}{|c|}{$\beta$ coefficient $(95 \% \mathrm{CI})$} & $p$ value & \multicolumn{2}{|c|}{$\beta$ coefficient $(95 \% \mathrm{Cl})$} & $p$ value \\
\hline \multicolumn{7}{|l|}{ Gestational } \\
\hline Weight gain, kg & 13.13 & (4.04 to 22.17 ) & 0.005 & 13.73 & (4.73 to 22.73 ) & $<0.001$ \\
\hline Age, wk & 24.73 & (1.88 to 47.60$)$ & 0.035 & 25.19 & (2.28 to 48.10$)$ & 0.032 \\
\hline \multicolumn{7}{|l|}{ Maternal } \\
\hline Age, yr & -13.74 & $(-24.40$ to -3.30$)$ & 0.012 & -14.69 & $(-25.39$ to -3.99$)$ & 0.008 \\
\hline Height, cm & 83.08 & (32.84 to 133.32 ) & 0.001 & 87.38 & (37.13 to 137.62 ) & $<0.001$ \\
\hline Education, yr $\neq$ & 112.99 & (7.89 to 218.09 ) & 0.036 & 111.92 & (6.63 to 217.21 ) & 0.038 \\
\hline Body mass index, $\mathrm{kg} / \mathrm{m}^{2}$ & 24.89 & (11.62 to 38.16$)$ & $<0.001$ & 26.68 & (13.37 to 39.99$)$ & $<0.001$ \\
\hline Milk intake, L & 9.75 & (3.30 to 17.77$)$ & 0.016 & & NA & \\
\hline Cups* & 41.21 & (13.96 to 75.12 ) & & & NA & \\
\hline Vitamin D intake, $\mu \mathrm{g} / \mathrm{d} \dagger$ & & NA & & 10.97 & (1.19 to 20.75$)$ & 0.029 \\
\hline \multicolumn{7}{|c|}{$\begin{array}{l}\text { Note: } \mathrm{Cl}=\text { confidence interval, } \mathrm{NA}=\text { not applicable. } \\
\text { "Intercept }=-141.57, \text { overall } R^{2}=0.1806, F=7.93, p<0.0001 \text { for the model. After controlling for gestational weight gain and } \\
\text { maternal age, height, education and body mass index, every } 250 \text {-mL (1-cup) increase in daily milk intake was associated with } \\
\text { an increase in infant birth weight of } 41.2 \mathrm{~g} \text {. } \\
\text { †Intercept }=-332.65 \text {, overall } R^{2}=0.1773, F=7.76, p<0.0001 \text { for the model. After controlling for the above factors, every } \\
1-\mu \mathrm{g} \text { increase in daily vitamin } \mathrm{D} \text { intake was associated with an increase in infant birth weight of } 11.0 \mathrm{~g} \text {. } \\
\text { FCategorized as those with university education and those without. }\end{array}$} \\
\hline
\end{tabular}

low concentrations of insulin-like growth factor (IGF-1) in maternal and umbilical cord serum from women with preeclampsia and infants who are small for their gestational age. ${ }^{35}$ Women who practice milk restriction reportedly experience diminished serum concentrations of vitamin $\mathrm{D}$ and calcium, and decreased third-trimester weight gain. ${ }^{36}$ One author $^{37}$ has reported an inverse association between calcium absorption and birth weight that was partially explained by vitamin D intake. Thus, our study demonstrates that in pregnant women living where sun conditions for year-round vitamin D synthesis are less than ideal, ${ }^{12,30,31}$ poor vitamin D intake from food sources (including fortified milk) and failure to select appropriate vitamin and mineral supplementation can result in lower infant birth weight.

In the past few years, it has been suggested that currently recommended vitamin $\mathrm{D}$ intakes may be too low to prevent insufficiency in the general population. ${ }^{15,38,39}$ Some authors ${ }^{39,40}$ have urged higher intake recommendations for vitamin D in North America for those living at or above latitudes ranging from $42^{\circ}$ to $52^{\circ} \mathrm{N}$, similar to practices in European countries. ${ }^{41}$ Our study results suggest that increased recommendations for vitamin D intake should extend to pregnant women. Current recommendations to restrict intake of fortified milk are clearly ill-advised for those living at latitudes where dermal conversion of 7-dehydrocholecalciferol to active vitamin D is seasonally limited. Fortified milk provides an important source of vitamin D and calcium, and contributes to adequate protein intake. Practitioners should query pregnant women about their consumption of fortified milk and multivitamins, specifically those containing vitamin $\mathrm{D}$, to avoid the risk of lowered birth weight as a result of insufficient intake, particularly when and where sun exposure is limited.
This article has been peer reviewed.

From the Faculty of Nursing (Mannion), University of Calgary, Calgary, Alta. and the School of Dietetics and Human Nutrition (Koski, Gray-MacDonald, Koski) and the Faculty of Medicine (Koski), McGill University, Ste. Anne de Bellevue, Que.

Competing interests: None declared.

Contributors: Kristine Koski conceived the idea that milk restriction might be related to poor fetal growth. She and Katherine Gray-Donald received funding to conduct the study, which was implemented and managed by Cynthia Mannion. All authors were involved in data analysis, drafting the paper and revising it. All authors edited the final submission and approved this article in its final form.

Acknowledgements: We are grateful to Louise Johnson-Down for her help with the nutrient analyses.

Funding sources for our study included the Dairy Farmers of Canada and FRSQ, Fonds de recherche en Santé du Québec.

\section{REFERENCES}

I. Chandra RK. Food allergy and nutrition in early life: implications for later health. Proc Nutr Soc 2000;59:273-7.

2. Godfrey KM, Barker DJ, Robinson S, et al. Maternal birthweight and diet in pregnancy in relation to the infant's thinness at birth. BrJ Obstet Gynaecol I997;104:663-7.

3. Giddens JB, Krug SK, Tsang RC, et al. Pregnant adolescent and adult women have similarly low intakes of selected nutrients. J Am Diet Assoc 2000;100:1334-40.

4. Ortega RM, Quintas ME, Martinez RM, et al. Riboflavin levels in maternal milk: the influence of vitamin B2 status during the third trimester of pregnancy. J Am Coll Nutr 1999;18:324-9.

5. Di Cintio E, Parazzini F, Chatenoud L, et al. Dietary factors and risk of spontaneous abortion. Eur J Obstet Gynecol Reprod Biol 200I;95:132-6.

6. Duvekot EJ, de Groot CJ, Bloemenkamp KW, et al. Pregnant women with a low milk intake have an increased risk of developing preeclampsia. Eur J Obstet Gynecol Reprod Biol 2002;105:II-4.

7. Bulloch B, Schubert CJ, Brophy PD, et al. Cause and clinical characteristics of rib fractures in infants. Pediatrics 2000;105:E48.

8. Marya RK, Rathee $S$, Lata V, et al. Effects of vitamin D supplementation in pregnancy. Gynecol Obstet Invest I981;12:155-61.

9. Sanchez DJ, Murphy MM, Bosch-Sabater J, et al. Enzymic evaluation of thiamin, riboflavin and pyridoxine status of parturient mothers and their newborn infants in a Mediterranean area of Spain. Eur J Clin Nutr 1999;53:27-38. 
Io. Badart-Smook $\mathrm{A}$, van Houwelingen $\mathrm{AC}, \mathrm{Al} \mathrm{MD}$, et al. Fetal growth is associated positively with maternal intake of riboflavin and negatively with maternal intake of linoleic acid. JAm Diet Assoc 1997;97:867-70.

II. Starkey LJ, Johnson-Down L, Gray-Donald K. Food habits of Canadians: comparison of intakes in adults and adolescents to Canada's Food Guide to Healthy Eating. Can J Diet Pract Res 200I;62:6I-9.

I2. Webb AR, Kline L, Holick MF. Influence of season and latitude on the cutaneous synthesis of vitamin $\mathrm{D}_{3}$ : exposure to winter sunlight in Boston and Edmonton will not promote vitamin $\mathrm{D}_{3}$ synthesis in human skin. J Clin Endocrinol Metab I988; $67: 373-8$.

I3. Holick MF. Environmental factors that influence the cutaneous production of vitamin D. Am J Clin Nutr I995;6r:638S-45S.

I4. Ovesen L, Andersen R, Jakobsen J. Geographical differences in vitamin D status, with particular reference to European countries. Proc Nutr Soc 2003;62:813-2I.

I5. Glerup H, Mikkelsen K, Poulsen L, et al. Commonly recommended daily intake of vitamin D is not sufficient if sunlight exposure is limited. J Intern Med 2000;247: 260-8.

I6. Grover SR, Morley R. Vitamin D deficiency in veiled or dark-skinned pregnant women. Med J Aust 200I;175:25I-2.

I7. Milk, Nutrition Communications: Making Healthy Eating Easy. Milk facts: nutrients in milk. Available: www.media@milknutrition.org/media/index.html (accessed 2006 Feb 20)

I8. Casey PH, Goolsby SL, Lensing SY, et al. The use of telephone interview methodology to obtain 24-hour dietary recalls. J Am Diet Assoc 1999;99:I406-II.

I9. Galasso R, Panico S, Celentano E, et al. Relative validity of multiple telephone versus face-to-face 24-hour dietary recalls. Ann Epidemiol I994;4:332-6.

20. Health Canada. Canadian Nutrient File. Ottawa: Health Canada; I997. Available: www.hc-sc.gc.ca/fn-an/nutrition/fiche-nutri-data/index_e.html (accessed 2006 Mar I9).

2I. Adams CF. Nutritive value of American foods in common units. Agricultural Handbook No. 456. Washington: Agricultural Research Services, US Department of Agriculture; 1975 .

22. National Research Council. Nutrient adequacy: assessment using food consump tion surveys. Washington: National Academy Press; 1986.

23. Institute of Medicine. Dietary reference intakes: applications in dietary assessment. Washington: National Academy Press; 2000.

24. National Academy of Sciences. Dietary reference intakes for energy, carbohydrate fiber, fat, fatty acids, cholesterol, protein and amino acids (macronutrients) (2005) Available: www.nap.edu/openbook/0309085373/html (accessed 2006 Feb 20).

25. Kramer MS. Determinants of low birth weight: methodological assessment and meta-analysis. Bull World Health Organ 1987;65:663-737.

26. Hagy LF, Brochetti D, Duncan SE. Focus groups identified women's perceptions of dairy foods. JWomen Aging 2000;12:99-II5.

27. Cashel K, Crawford D, Deakin V. Milk choices made by women: what influence them, and does it impact on calcium intake? Public Health Nutr 2000;3:403-10.

28. Chapman KM, Chan MW, Clark CD. Factors influencing dairy calcium intake in women. J Am Coll Nutr 1995; 14:336-40.

29. Gulliver P, Horwath CC. Assessing women's perceived benefits, barriers, and stage of change for meeting milk product consumption recommendations. J Am Die Assoc 200I; IOI: I354-7.

30. Vieth R, Cole DE, Hawker GA, et al. Wintertime vitamin D insufficiency is common in young Canadian women, and their vitamin $\mathrm{D}$ intake does not prevent it. Eur J Clin Nutr 200I;55:I09I-7.

3I. Rucker D, Allan JA, Fick GH, et al. Vitamin D insufficiency in a population of healthy western Canadians. CMAJ 2002; 166:1517-24.

32. Weiler $\mathrm{H}$, Fitzpatrick-Wong $\mathrm{S}$, Veitch $\mathrm{R}$, et al. Vitamin $\mathrm{D}$ deficiency and whole-bod and femur bone mass relative to weight in healthy newborns. CMAJ 2005;172(6): 757-6r.
33. Marya RK, Rathee S, Dua V, et al. Effect of vitamin D supplementation during pregnancy on foetal growth. Indian J Med Res I988;88:488-92.

34. Cockburn F, Belton NR, Purvis RJ, et al. Maternal vitamin D intake and minera metabolism in mothers and their newborn infants. $B M J \mathrm{I} 980 ; 28 \mathrm{I}: \mathrm{II}-4$.

35. Halhali A, Tovar AR, Torres N, et al. Preeclampsia is associated with low circulating levels of insulin-like growth factor I and 1,25-dihydroxyvitamin D in maternal and umbilical cord compartments. J Clin Endocrinol Metab 2000;85:1828-33.

36. Specker BL. Do North American women need supplemental vitamin D during pregnancy or lactation? Am J Clin Nutr 1994;59:484S-90S.

37. Arden NK, Major P, Poole JR, et al. Size at birth, adult intestinal calcium absorption and $\mathrm{I}, 25(\mathrm{OH})$, vitamin D. QJM 2002;95:I5-2I.

38. Hollis BW, Wagner CL. Assessment of dietary vitamin D requirements during pregnancy and lactation. Am J Clin Nutr 2004;79:717-26.

39. Vieth R, Fraser D. Vitamin D insufficiency: no recommended dietary allowance exists for this nutrient. $C M A J$ 2002; 166 (I2):I54I-2

40. Ritchie LD, King JC. Dietary calcium and pregnancy-induced hypertension: Is there a relation? Am JClin Nutr 2000;71:137IS-4S.

4I. Erkkola M, Karppinen M, Jarvinen A, et al. Folate, vitamin D, and iron intakes are low among pregnant Finnish women. Eur J Clin Nutr 1998;52:742-8.

Correspondence to: Dr. Kristine Koski, Director, School of Dietetics and Human Nutrition, McGill University, 2 III rue Lakeshore, Ste. Anne de Bellevue, QC $\mathrm{Hg}_{9} \mathrm{~V}_{9}$; kristine.koski@mcgill.ca

\section{Editor's take}

- Women increasingly restrict milk intake during pregnancy for a variety of reasons. Does this have an effect on their infants' birth weight?

- In this study, women whose daily consumption of milk during pregnancy was 1 cup ( $250 \mathrm{~mL}$ ) or less consumed less protein and vitamin $\mathrm{D}$ and gave birth to smaller babies than did mothers who drank more milk. Every 1 -cup increase in daily milk consumption increased birth weight by $41 \mathrm{~g}$; each $1-\mu \mathrm{g}$ increase in daily vitamin $D$ intake increased it by $11 \mathrm{~g}$.

Implications for practice: Clinicians should be alert to the effects of milk restriction and its associated reduction in vitamin D intake, and encourage pregnant women to maintain milk consumption. Adequate intake of vitamin D is especially important during winter months. 